\title{
AC Railway Electrification Systems - an EMC Perspective
}

\author{
Zhouxiang Fei, Tadeusz Konefal, and Rob Armstrong* \\ Corresponding author: Rob Armstrong \\ Eurofins York Ltd, Arabesque House, Monks Cross Drive, Huntington, York, YO32 9GW, U.K. \\ Email: zhouxiangfei@eurofins.com, tadkonefal@eurofins.com,robarmstrong@eurofins.com
}

\begin{abstract}
Railways are electrified in many different ways. In this article, the main options for electrifying a high speed $A C$ railway are reviewed from an electromagnetic compatibility (EMC) perspective. Firstly, the trend of increasing the usage of electrified trains to replace conventional diesel locomotives is pointed out. On this basis, the significance of considering EMC in the railway environment is explained, with a view to preventing the malfunction of the railway system. Secondly, different electrification options are introduced, namely the rail-return, boostertransformer and auto-transformer systems. The benefits and drawbacks of each electrification option are considered based on the interference level to the trackside railway signalling and telecommunication systems. The discussion of each electrification system is verified using electromagnetic simulations. By comparing the different electrification schemes, it is shown that the auto-transformer system has better EMC performance and delivers higher power to the train.
\end{abstract}

Index Terms - Electromagnetic compatibility, railway electrification, trackside signalling system

\section{Introduction}

Since the first application in the early nineteenth century, railway systems have reshaped the way of transporting cargo and passengers over long distances. The most significant components of the railway system are the trains consisting of a series of vehicles (i.e., rolling stocks) connected together and running on railway tracks.

Historically, the motive power of the train was generated using steam and diesel (still being used today). However, there has been a trend to move towards electric locomotives powered by railway electrification systems. There are many good reasons to use electrified railway systems. For example, the traction of electric trains has a higher power-to-weight ratio compared to that 
of diesel trains. Moreover, the use of electric trains can significantly reduce the carbon footprint compared to traditional diesel locomotives.

As one may imagine, due to the deployment of railway electrification systems, the railway electromagnetic environment becomes significantly harsher and more complex. As a result, the railway system may become more exposed to potential systematic degradations. For example, the signalling system [1] used for detecting the presence of trains on tracks may experience faulty operation. Therefore, engineers need to ensure that the electronic/electrical systems in the electrified railway system work as intended.

To gain such confidence, engineers need to evaluate the performance of the electrified railway system from an electromagnetic compatibility (EMC) [2] perspective. In general, the aim of EMC is to ensure that systems function satisfactorily in the electromagnetic environment without introducing intolerable disturbance to each other. The EMC issue is particularly important in the railway electromagnetic environment [3]. This is due to its safety-critical feature and the increasing number of electrical systems with high level of electromagnetic emissions. As a result, strong electromagnetic coupling inevitably exists between different systems in the railway environment, causing functional degradation. Therefore, it is of great significance to consider railway EMC issues throughout the life cycle of the railway. The standard suite EN50121 [4] contains essential requirements for demonstrating EMC compliance in the railway environment.

The aim of this article is to evaluate the main electrification schemes for high speed alternating current (AC) railways from an EMC perspective. The relative benefits and drawbacks of each option are detailed and shown using simulation. To this end, the working principles of different electrification schemes need to be understood. The remainder of this article is organised as

follows: Section 2 presents an overview of the different railway electrification schemes, including the rail-return [5], booster-transformer [5], and auto-transformer systems [6]. The relative benefits and drawbacks of each system are discussed. The simulation results of each electrification scheme are presented in Section 3. The EMC performance of each system is then evaluated by comparing the simulation results. Finally, the conclusions of this article are given in Section 4.

\section{Fundamentals of Railway Electrification Systems}

The history of the first electric train can date back to the year 1890 for London Underground. Electric locomotives can be powered by AC or direct current (DC) electrification systems. In the $A C$ electrification scheme, the electricity is fed to the locomotive from an overhead power line $(\mathrm{OHL})$ suspended above the locomotive. An example of the OHL system is shown in Figure 1. In the DC electrification system, the train normally draws electricity from a third rail placed aside the railway track. A typical third rail electrification configuration of $750 \mathrm{~V}$ is given in Figure 2 . 
Please note that the OHL configuration is still possible in DC electrification systems but this is not common, such as the OHL DC (1500 V) tram system. Due to the variety of railway electrification schemes worldwide, the descriptions presented in this article are based on the UK applications.

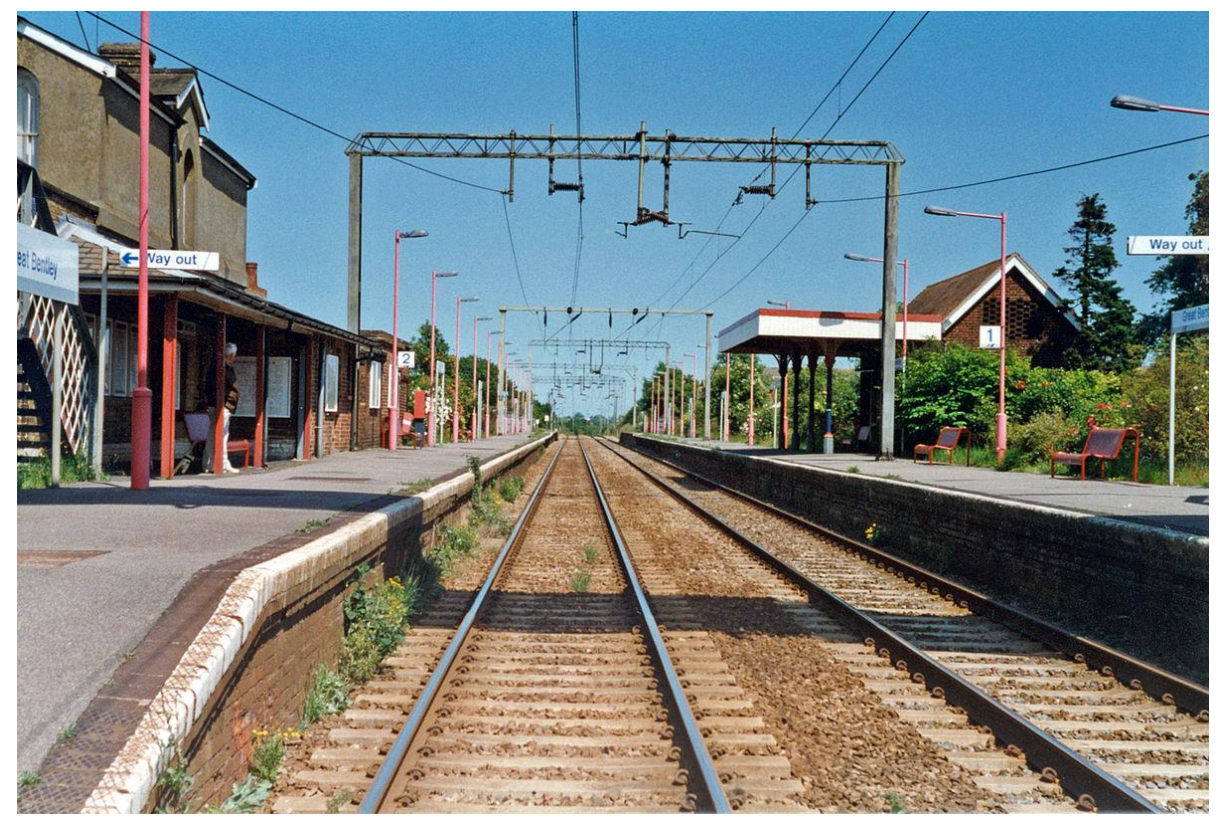

Figure 1. Overhead line electrification system [7].

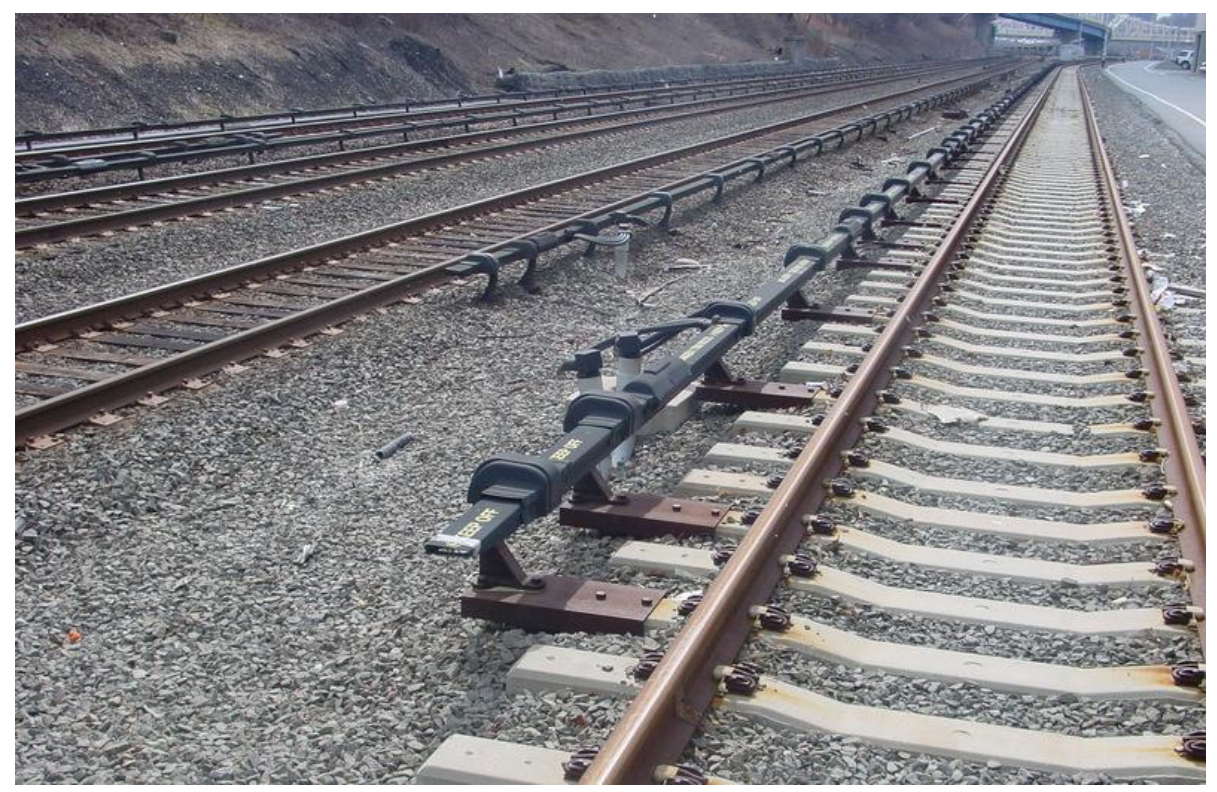

Figure 2. Third rail electrification system [8].

There has been a trend to replace the third rail system with the OHL topology. The reasons are: (1) a maximum train speed of $160 \mathrm{~km} / \mathrm{h}$ is imposed in third rail systems, (2) the power consumption efficiency in a third rail system is lower compared to that of an OHL system, and (3) the third rail system poses a high risk of electric shock to people such as railway workers or 
trespassers. For these reasons, this article focuses on AC railway electrification systems with the $\mathrm{OHL}$ configuration. However, please note that the third rail system is still a good option in tunnels where the size of the system needs to be compact.

Under the OHL framework, there are three main railway electrification systems used in the UK, including the rail-return system, booster-transformer system, and auto-transformer system. These systems mainly differ in the way that: (1) the traction current is fed into the locomotive, and (2) the return current leaving the train flows back to the substation. Here, the substation is the electric power supply of the railway system. The traction current refers to the current flowing from the $\mathrm{OHL}$ into the train. The principle benefits and drawbacks of the three electrification systems are presented in the following sections. Let us first look at the rail-return electrification system.

\subsection{Rail-Return System}

The rail-return (RR) system has the simplest schematic of the three electrification systems. Figure 3 shows a simplified schematic containing all the essential components of a rail-return electrification system. In Figure 3, the substation feeding the train is represented by a $25 \mathrm{kV}$ (50 $\mathrm{Hz}$ ) voltage source. The red (solid) arrow denotes the traction current flowing via the overhead line into the locomotive. The green (dashed) arrow indicates the path of the return current back to the substation. It is clear that in the rail-return system, the traction current goes from the substation, then flows along the overhead line, and finally is fed into the locomotive via the pantograph. The pantograph is a device mounted on the roof of the train to collect electric power from the overhead power line. On the other hand, the rail track is used as the return conductor for the current to flow from the train and back to the substation. As shown in Figure 3, please note that a significant portion of the train current may also return to the substation via the ground, depending on the earthing strategy of the rail.

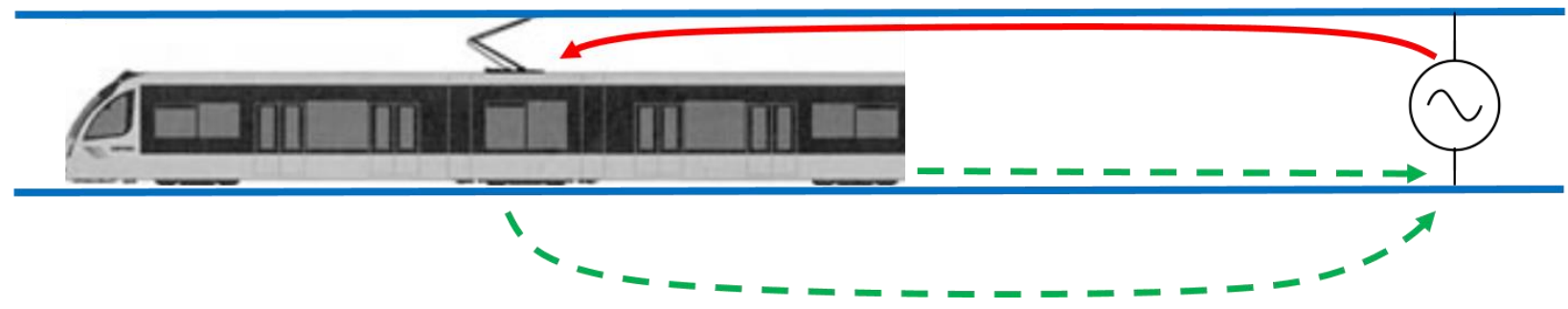

Figure 3. Simplified rail-return electrification system [9].

Let us focus on the EMC performance of the rail-return system. In this article, the interference sources are the overhead line and return conductor. This is because the magnetic field generated by the large loop area of the traction and return currents can induce significant voltage in nearby circuits. Both lineside signalling and telecoms cables are present and may be interfered with. 
These lineside cables are typically placed next to the rail along the railway route. The interference induced into the lineside cabling could cause the incorrect detection of the train position, resulting in a critical situation or delays to the train schedule.

As shown in Figure 3, the current direction in the overhead line is opposite to that in the return rail. To reduce the loop area and therefore the net inductive coupling into the lineside cabling, one solution is to place the overhead line and return conductor as close as possible. This is because the size of the loop area made by the traction circuit (consisting of the red and green paths in Figure 3) affects the induced voltage (i.e., interference) in the lineside cable [10]. Typically, the induced voltage level can be reduced by reducing the loop area of the traction circuit. In practice, this can be achieved by placing the return conductor at an overhead position in proximity to the overhead line. More details are given in Section 2.2.

The separation between the overhead line and return conductor in the rail-return, boostertransformer and auto-transformer systems is $5.4 \mathrm{~m}, 3.0 \mathrm{~m}$ and $3.0 \mathrm{~m}$, respectively. Therefore, the rail-return system has the largest separation between the overhead line and return conductor. As a result, the rail-return system is likely to produce a high level of interference to lineside victim cables. This can be verified using the simulation presented in Section 3.

Therefore, the drawback of the rail-return system is the potential excessive interference induced in the lineside cable. The benefit of the rail-return system is also straightforward: due to the configurational simplicity, the construction of the rail-return system is less costly in terms of the involved labour and investment.

Clearly, to reduce the inductive coupling from the electrification system, one needs to reduce the separation between the $\mathrm{OHL}$ and return conductor. This idea gives rise to the boostertransformer electrification system in Section 2.2.

\subsection{Booster-Transformer System}

Before introducing the booster-transformer (BT) electrification system, it is necessary to further understand the importance of placing the return conductor at the overhead position. In fact, the overhead return conductor is one of the key techniques to reduce the electrification system emission to nearby apparatus.

The mechanism of the interference reduction using the overhead return conductor is shown in Figure 4. As can be seen from the cross-section of a railway electrification system, the return conductor of the train current is placed overhead and closer to the overhead power line, in a position of symmetry with respect to the victim cabling. As a result, instead of having all the return current flowing via the railway track, now there is a significant portion of the return current flowing back to the substation via the overhead return conductor. 
Consequently, at any position along the lineside cable (e.g. cable end $A$ in Figure 4 ), the magnetic fields generated by the $\mathrm{OHL}$ and overhead return conductor are of opposite directions but similar magnitude. Therefore, the magnetic fields penetrating the cable are significantly cancelled out, resulting in a very small amount of net inductive coupling to the lineside cable. As a result, the interference induced in the lineside signalling cable is much reduced, compared to the rail-return system case. In practice, the overhead return conductor is typically bonded to the railway track every $3.2 \mathrm{~km}$.

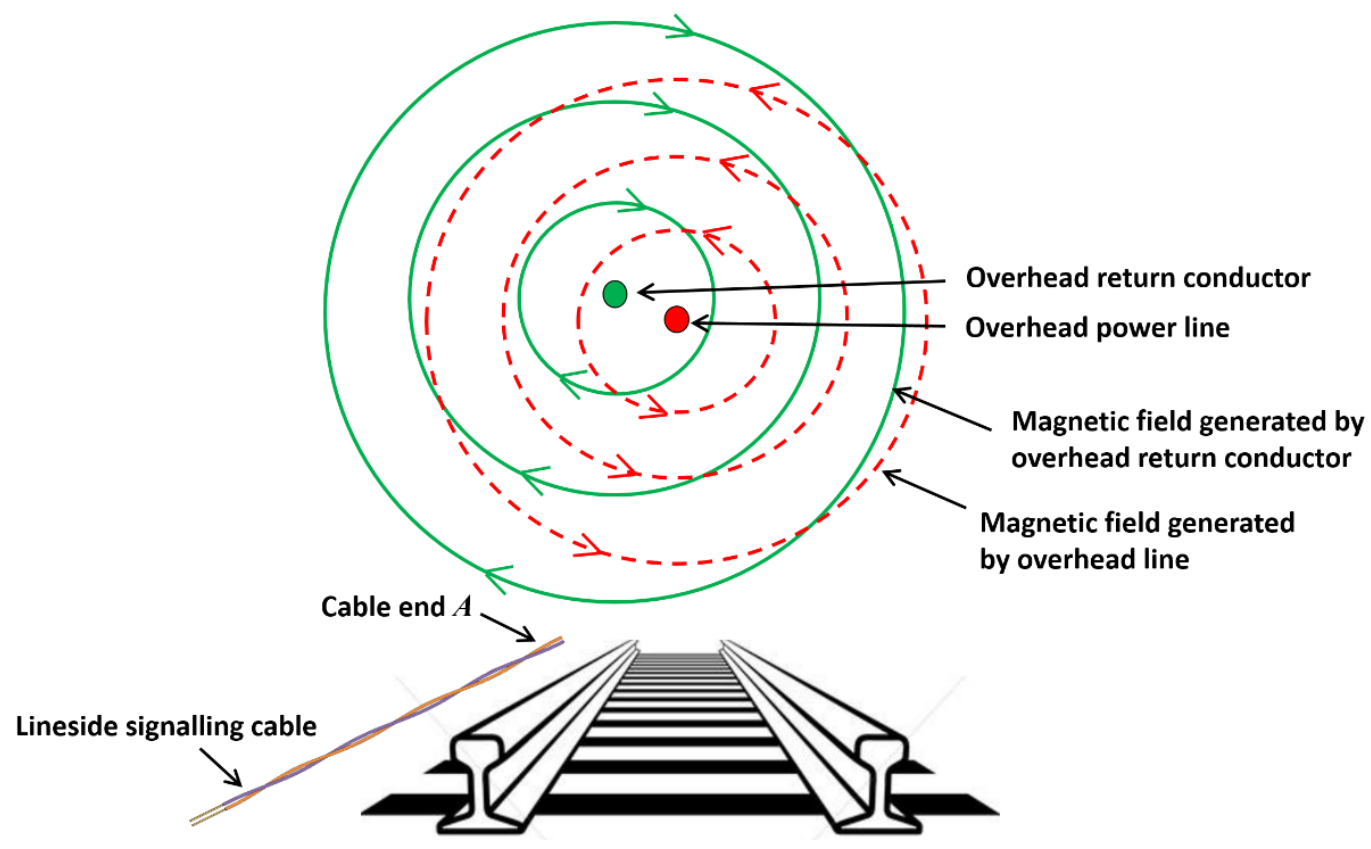

Figure 4. Magnetic field cancellation using overhead return conductor [9].

However, placing the return conductor at the overhead position may not always be sufficient. In other words, excessive interference level in lineside cables is still possible. This is because in the sole presence of the overhead return conductor, there is still a considerable amount of current returning to the substation via the rail. Please see Figure 5 for an approximation of the current return loop. Ideally, all the train current is expected to return via the overhead return conductor. In this way, the magnetic field magnitude of the overhead return conductor becomes closer to that of the $\mathrm{OHL}$, and is further cancelled out. As a result, the net inductive coupling at the victim lineside cable can be reduced. Therefore, there is a need to drive the train current to return via the overhead return conductor as much as possible.

Considering this motivation, the booster-transformer electrification system is introduced to the railway world. The simplified schematic of the booster-transformer system is given in Figure 5. Here, the substation produces $25 \mathrm{kV}(50 \mathrm{~Hz})$ to energise the railway system. As can be seen, the booster-transformer system uses overhead return conductors as the return path of the train current. Booster transformers are used to pull up the train current from the railway track to the overhead return conductor as much as possible. Specifically, the booster transformer consists of 
a pair of primary and secondary windings which are magnetically coupled and identical. The primary winding of the booster transformer is placed in series with the $\mathrm{OHL}$, and the secondary winding is installed in series with the overhead return conductor. As a result, the return current in the overhead return conductor is forced to be nearly equal to the current in the OHL. Thus, the return current flowing in the rail is effectively reduced. In Figure 5, the red (solid) arrow shows the path of the $\mathrm{OHL}$ current feeding the train, and the green (dashed) arrow indicates the return path of the current back to the substation. In practice, booster transformers are typically placed every $3.2 \mathrm{~km}$ along the railway route.

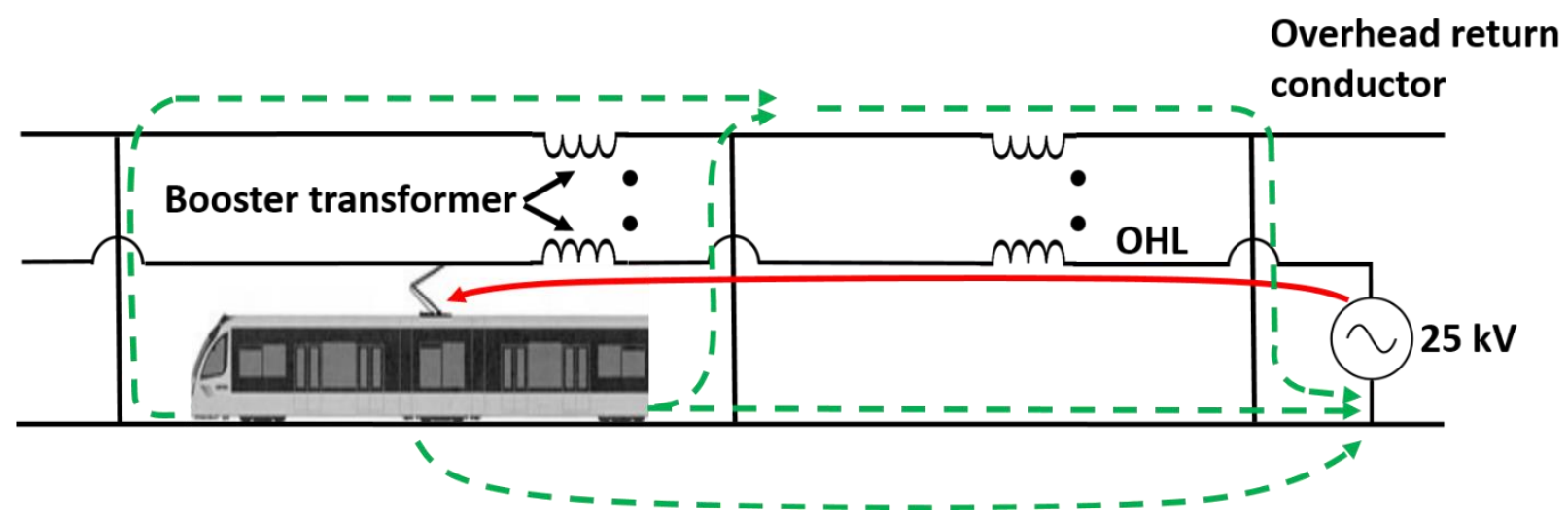

Figure 5. Simplified booster-transformer electrification system [9].

In brief, the aim of the BT electrification system is to force nearly all the return currents to flow back to the substation via the overhead return conductor. This is due to the magnetic coupling between the primary and secondary windings of the booster transformer. As discussed previously, the currents in the overhead return conductor and $\mathrm{OHL}$ now have very similar magnitude but flow in opposite directions. As a result, the magnetic fields generated by the electrification system are significantly cancelled out, leading to a considerable reduction of interference into the lineside cables. Please note that the phase angle is not considered on multiconductor transmission line in this article. The frequency range considered in this article is from $50 \mathrm{~Hz}$ to $50 \mathrm{kHz}$. This is because most of the train detection devices (e.g. track circuits and axle counters) operate within this frequency range.

In summary, the benefit of the booster-transformer electrification system is to significantly reduce the interference to lineside signalling system, thus mitigating the risk of signalling degradation. However, it is also worth pointing out the drawback of the booster-transformer system. Specifically, the booster transformer introduces a high impedance value along the OHL. This high impedance reduces the supplied voltage across the locomotive, especially when multiple booster transformers are present within a section. As a result, the traction power of the train may be reduced due to the voltage drop across the booster transformer, which may impose constraints on the train speed. 
Therefore, in addition to generating small electromagnetic disturbance, an ideal railway electrification system is also expected to reduce the loss in the power transmission process. This motivation brings the auto-transformer electrification system introduced in Section 2.3.

\subsection{Auto-Transformer System}

Unlike the BT system suffering power loss, the auto-transformer (AT) electrification system can maintain high power capacity of the railway system. Therefore, the auto-transformer system is a good solution for running high-speed trains and heavy cargo transportation, where a high power level is required. For example, the auto-transformer system has been used as a standard electrification scheme for high-speed trains in Japan [11]. The history of the auto-transformer system can date back much earlier than people may imagine. In 1910, the auto-transformer system was already widely used in the U.S. and considered as a standard electrification scheme for heavy-duty and high-speed railway lines.

Before understanding the benefits of the auto-transformer system, let us first understand its working principle, as shown in Figure 6 . As can be seen, the voltage of $400 \mathrm{kV}(50 \mathrm{~Hz})$ from the national grid is transformed to $50 \mathrm{kV}(50 \mathrm{~Hz})$ at the substation to energise the auto-transformer electrification system. The centre tap of the transformer is earthed to provide $+25 \mathrm{kV}$ for the overhead power line, $0 \mathrm{~V}$ for the railway track, and -25 kV for the autofeeder line. Similar to the BT system configuration, the autofeeder line is also placed at the overhead position and acts as the return path of the train current back to the substation.

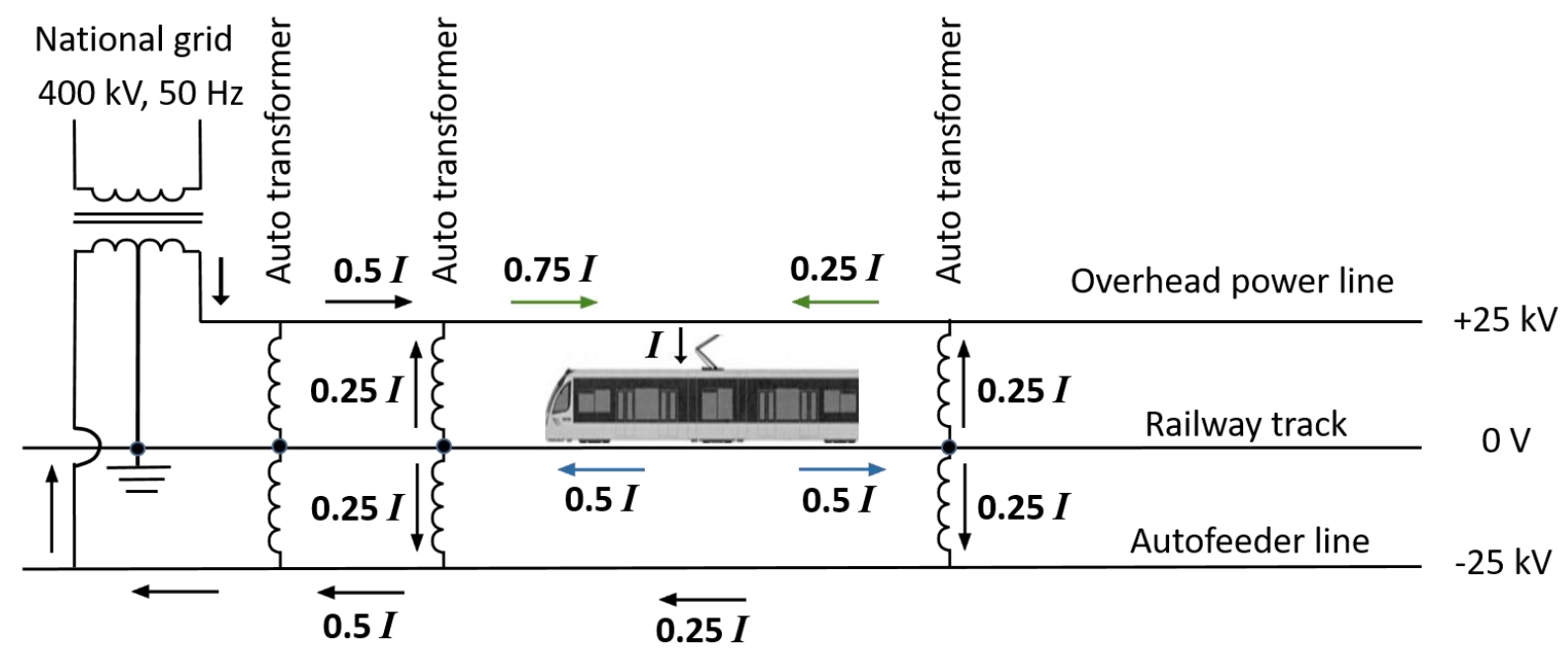

Figure 6. Simplified auto-transformer electrification system [9].

Now let us understand the high power capacity of the auto-transformer electrification system. Recalling the BT system configuration in Figure 5, the power loss to the train is due to voltage 
drop across the primary winding of the booster transformer in series with the OHL. However, as can be seen in Figure 6, there is no transformer placed in series with the OHL in the AT system. As a result, the power loss due to the voltage drop across the transformer is significantly reduced. Now the electric power can be efficiently delivered to the locomotive, as the voltage drop along the overhead power line is typically very small. Please note that although the AT electrification scheme provides $50 \mathrm{kV}$ to the railway system, the train is only drawing electric power from the $+25 \mathrm{kV}$ overhead power line. This is beneficial as trains operating in rail-return and boostertransformer systems can be directly used in the auto-transformer system.

Another reason for the low power loss in the AT system is the use of high-voltage transmission of electric power. Specifically, the AT system uses a higher voltage of $50 \mathrm{kV}$ to transmit electric power, compared to $25 \mathrm{kV}$ used in the BT system. The mechanism of reducing power loss in the AT system is the same as using the high-voltage transmission of electric power in the national grid. This is because in the power transmission process, the use of high voltage can reduce the current level flowing in the power line, resulting in a low power loss dissipated by the resistance of the power line. Due to the high power transmission efficiency of the AT system, substations can be placed further apart without suffering significant voltage drop along the OHL. As a result, the number of substations along the railway route can be reduced, thus reducing the railway infrastructure cost (substations can be very expensive).

Now let us focus upon the benefits of the AT electrification system from an EMC perspective. As the autofeeder line behaves as an overhead return conductor, the inductive coupling to the lineside cable can be considerably reduced due to the same mechanism explained in Section 2.2.

Apart from the interaction between the $\mathrm{OHL}$ and autofeeder line, the designated current directions in the AT system could further reduce the interference level. To demonstrate this point, the magnitude and direction of the current flowing in the AT system at $50 \mathrm{~Hz}$ are shown in Figure 6 . As can be seen in the $\mathrm{OHL}$, the currents marked with green arrows flow in opposite directions and are joined at the pantograph to energise the train. Due to the opposite current directions, the generated magnetic fields are cancelled out to a certain extent, thus reducing the coupling from the $\mathrm{OHL}$ to the lineside cable. The same mechanism of reducing interference can be found from the currents leaving the train in two opposite directions (marked with blue arrows in Figure 6).

In summary, compared with the BT system, the advantage of the AT system is the considerable reduction in the power loss during transmission. This is because in the AT system: (1) high-voltage transmission of electric power is used to feed the train, and (2) power loss due to transformer impedance is avoided. For this reason, the AT railway electrification system can competently serve heavy freight transportation and high-speed trains. In addition to the high efficiency of feeding the train, another benefit of the AT system is the low interference induced in the lineside signalling cable. 
As the configuration of the AT system is more complex compared with the BT system, the construction of the AT railway electrification system may become more expensive. However, due to the high power transmission efficiency of the AT electrification scheme, a smaller number of substations may be required to energise a long railway route. Therefore, the choice of the electrification scheme to proceed with could become a trade-off from an investment perspective.

Having understood the theories of main AC electrification schemes in the U.K., the model of each electrification system is simulated in Section 3 to evaluate the EMC performance from a simulation perspective.

\section{EMC Simulation of Different Electrification Systems}

In this section, the models of different railway electrification systems are simulated. The simulation result is discussed to evaluate the EMC performance of each electrification scheme. Specifically, the simulation of the rail-return system is presented and discussed in Section 3.1. The simulated EMC performance of the booster-transformer system is evaluated in Section 3.2. In Section 3.3, the simulation result regarding the EMC performance of the auto-transformer system is discussed. The electromagnetic simulation was performed using the railway electrification EMC simulation toolkit developed by Eurofins York Ltd [12]. To reflect an actual electrification system, the length of the railway electrification system is assumed to be $40 \mathrm{~km}$. The lineside victim cable is assumed to be $6 \mathrm{~km}$ long. The rail track is assumed to use the doublerail configuration [13]. The double-rail configuration means that both rails are used as the return path of the traction current. In practice, the lineside signalling system consists of many cables with different types. For the demonstration purpose, the lineside signalling system is modelled as a single wire in this section.

Please note that the result is only nominal based on the simulated configuration of the electrification system, and may deviate from the actual application. However, the result is still useful to comment on the EMC performances of different electrification systems.

\subsection{Simulation of the Rail-Return Electrification System}

The transverse and longitudinal views of the simulated rail-return electrification system are given in Figure 7. The substation is modelled as a voltage source of $25 \mathrm{kV}$, and the train is modelled as a load impedance of $83 \Omega$, so that a maximum traction current of $300 \mathrm{~A}$ is assumed along the $\mathrm{OHL}$. The train can be located at an arbitrary distance away from the substation. 
The separation between two rails is $1.44 \mathrm{~m}$, and the $\mathrm{OHL}$ is placed at $5.33 \mathrm{~m}$ above the mid-point of the track. The lineside signalling cable is placed $2 \mathrm{~m}$ away from the left rail. The interference strength is quantified using the induced voltage measured across a $10 \Omega$ resistor at the far-end of the lineside cable. Here, the near-end refers to the substation end, and the far-end means the end furthest away from the substation. The lineside cable is short circuited to the ground at the near-end.

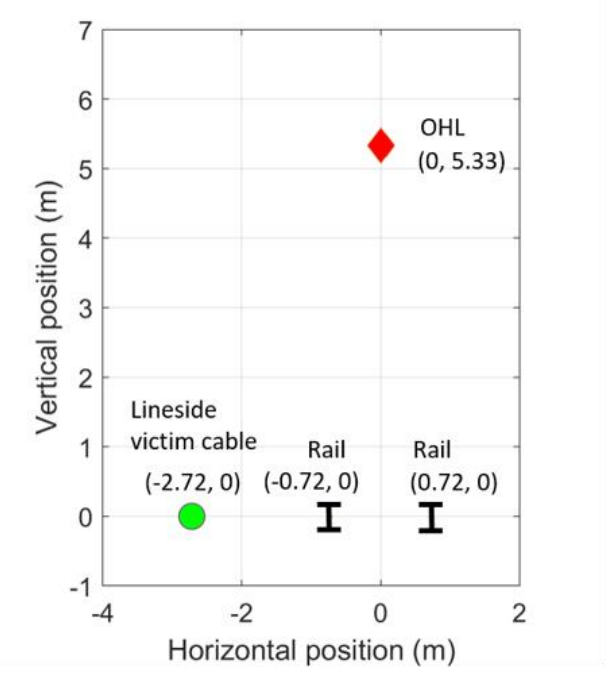

(a)

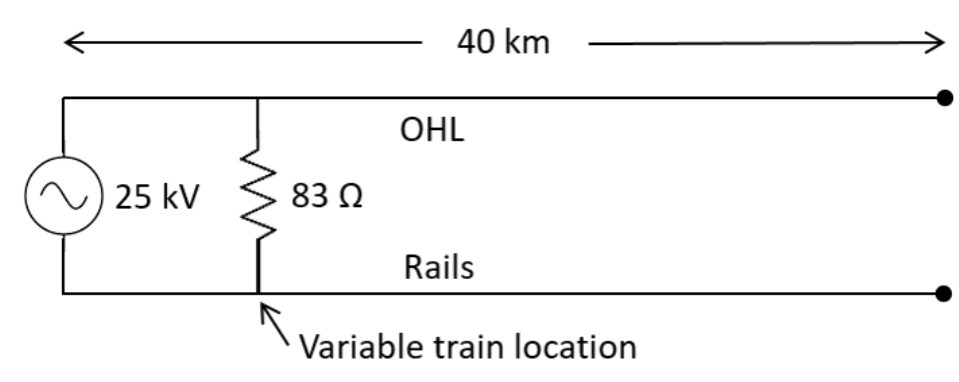

Lineside victim cable

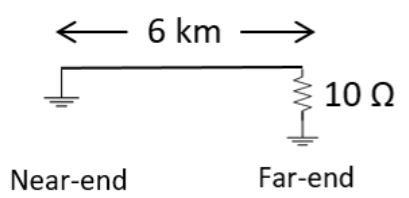

(b)

Figure 7. (a) Transverse view and (b) longitudinal view of the simulated rail-return electrification system.

Figure 8 shows the simulated interference level when the train is at $1 \mathrm{~km}, 2 \mathrm{~km}$ and $3 \mathrm{~km}$ away from the substation. It is clear that driving the train away from the substation (i.e., increasing the loop area of the traction circuit) generally increases the interference level. This result agrees with the interference mechanism explained in Section 2. 


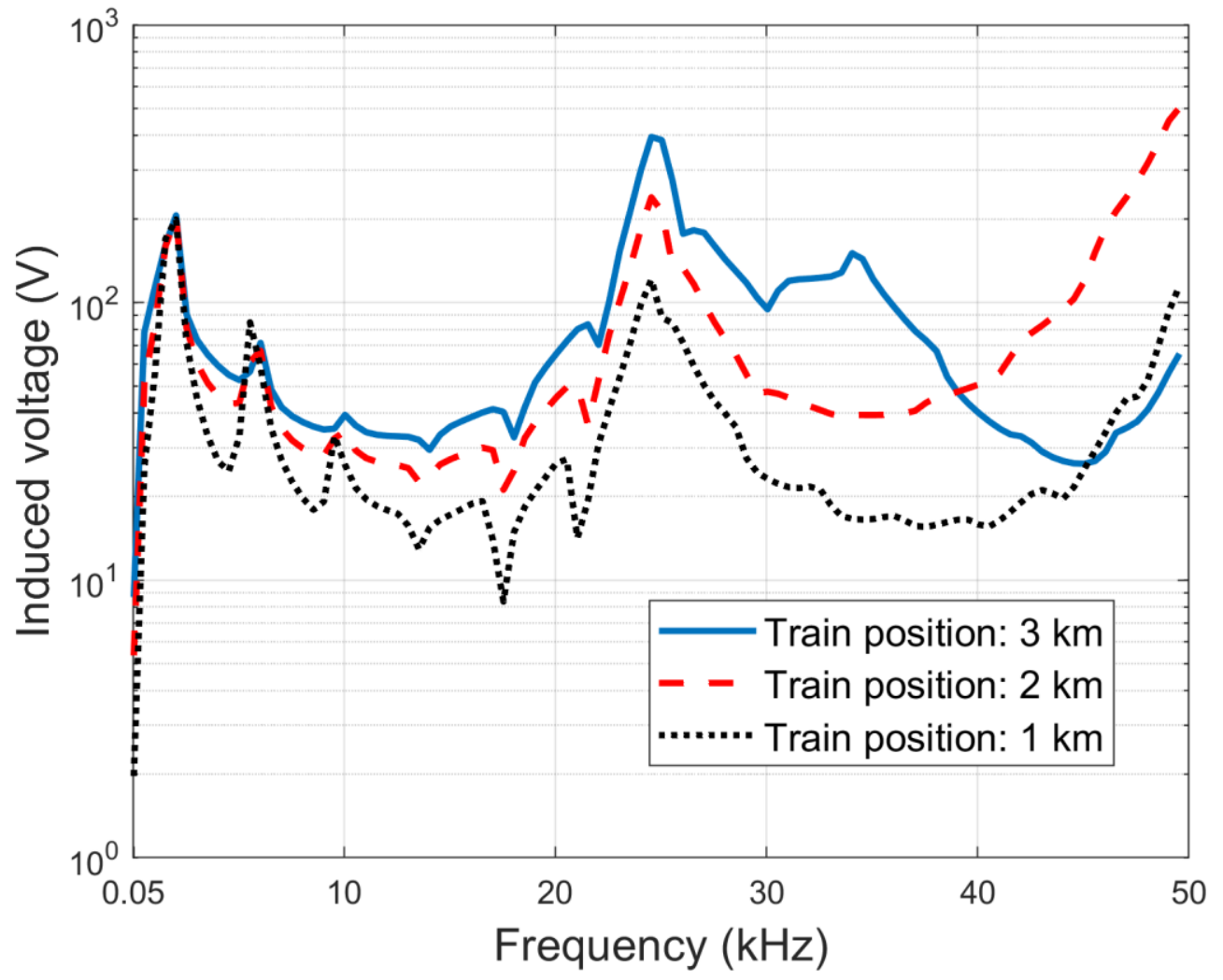

Figure 8. Induced voltage at the far-end of the lineside cable.

\subsection{Simulation of the Booster-Transformer Electrification System}

In this section, the EMC simulation of the BT electrification system is presented and discussed. The aim of the BT system is to use the booster transformer to return the traction current back to the substation via the overhead return conductor. As a result, the generated magnetic fields at the lineside cable can be effectively cancelled out, resulting in a reduced interference level.

The model of the simulated BT system is shown in Figure 9. Comparing to the RR system model in Figure 7, it is clear that an overhead return conductor is added in the BT system in Figure 9. The overhead return conductor is bonded to rails, so that traction current can flow from rails to the overhead return conductor. The first bonding point is $1.6 \mathrm{~km}$ away from the substation, and is repeated every $3.2 \mathrm{~km}$. The first booster transformer is $3.2 \mathrm{~km}$ away from the substation. The distance between two consecutive booster transformers is $3.2 \mathrm{~km}$. As a result, the simulated model reflects an actual booster-transformer electrification system. 


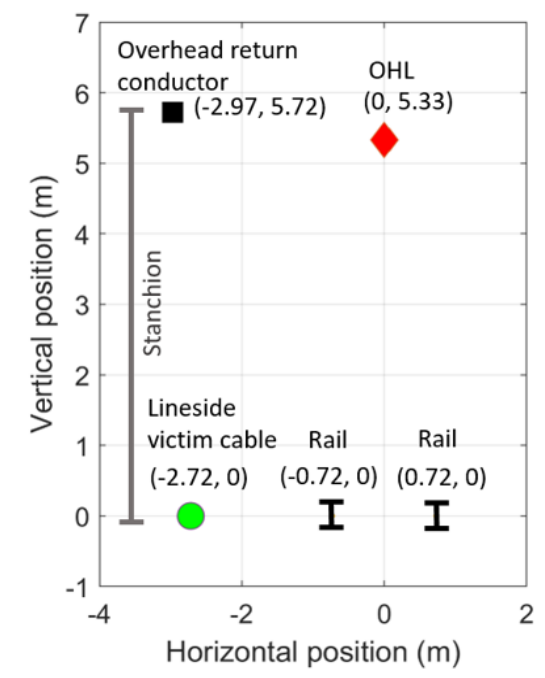

(a)
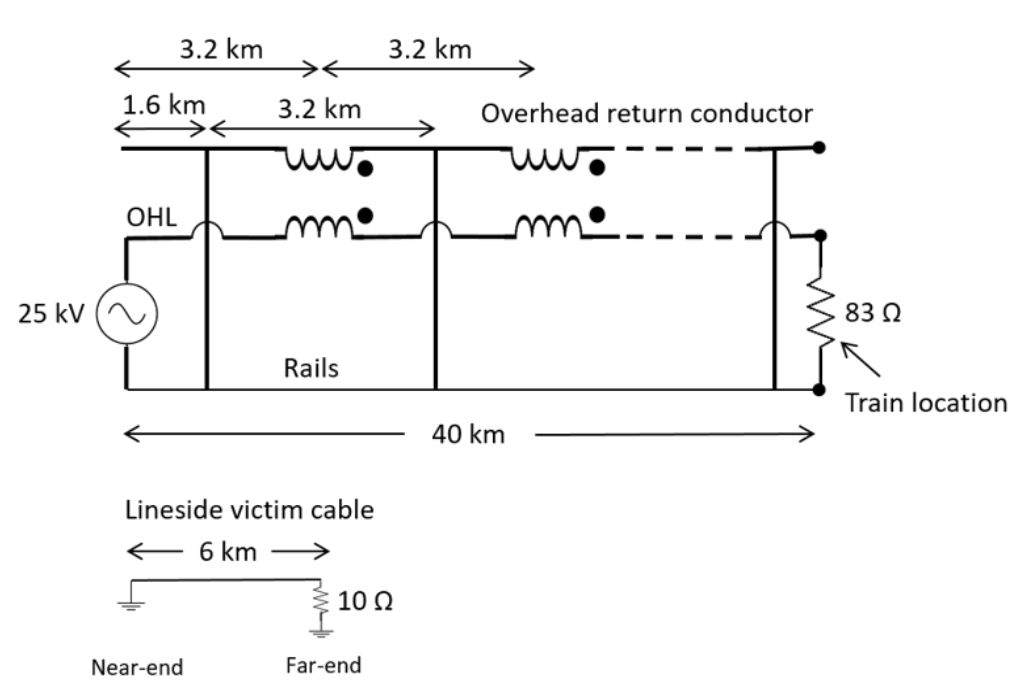

(b)

Figure 9. (a) Transverse view and (b) longitudinal view of the simulated booster-transformer electrification system.

As addressed in Section 2.2, the booster transformer consists of a primary winding (in series with the $\mathrm{OHL}$ ) and a secondary winding (in series with the overhead return conductor). The inductance of the booster transformer winding is normally a few tens of millihenries and is assumed to be $100 \mathrm{mH}$ in this article. In the model of Figure 9 , the train is $40 \mathrm{~km}$ away from the substation. Other features of the model remain the same as in Section 3.1.

Now let us evaluate the EMC performance of the simulated BT electrification system. In Figure 10 , the induced voltage at the far-end of the lineside cable under the BT electrification scheme is compared to the rail-return scenario (with the train placed $40 \mathrm{~km}$ away from the substation). As can be seen, the interference level in the BT electrification scheme is significantly smaller than the rail-return result, particularly at lower frequencies. Not only is the touch voltage at $50 \mathrm{~Hz}$ reduced, but many signaling systems operating in the frequency range below approximately 20 $\mathrm{kHz}$ will experience reduced interference on the lineside cable. Please note the large resonant peak at approximately $25 \mathrm{kHz}$ in Figure 10. This is due to the fact that the modelled lineside victim cable is terminated in a low impedance $(10 \Omega)$ at the far-end and via a short circuit at the nearend. The lineside victim cable will therefore experience a current antinode at each of its ends when the cable is half a wavelength long. For a $6 \mathrm{~km}$ cable, the first resonance will occur at the frequency of $25 \mathrm{kHz}$. Note that the voltage across the $10 \Omega$ resistor will similarly experience a peak as observed in Figure 10, since it is simply following the resonance in the current at the farend. It is worth noting that the first $1.6 \mathrm{~km}$ of the lineside cabling at the near-end is effectively experiencing rail-return coupling (see Figure $9(b)$ ), as no return current flows in the overhead return conductor within $1.6 \mathrm{~km}$ from the substation. By changing the location of the lineside cabling, the EMC performance of the BT system may be further improved. 


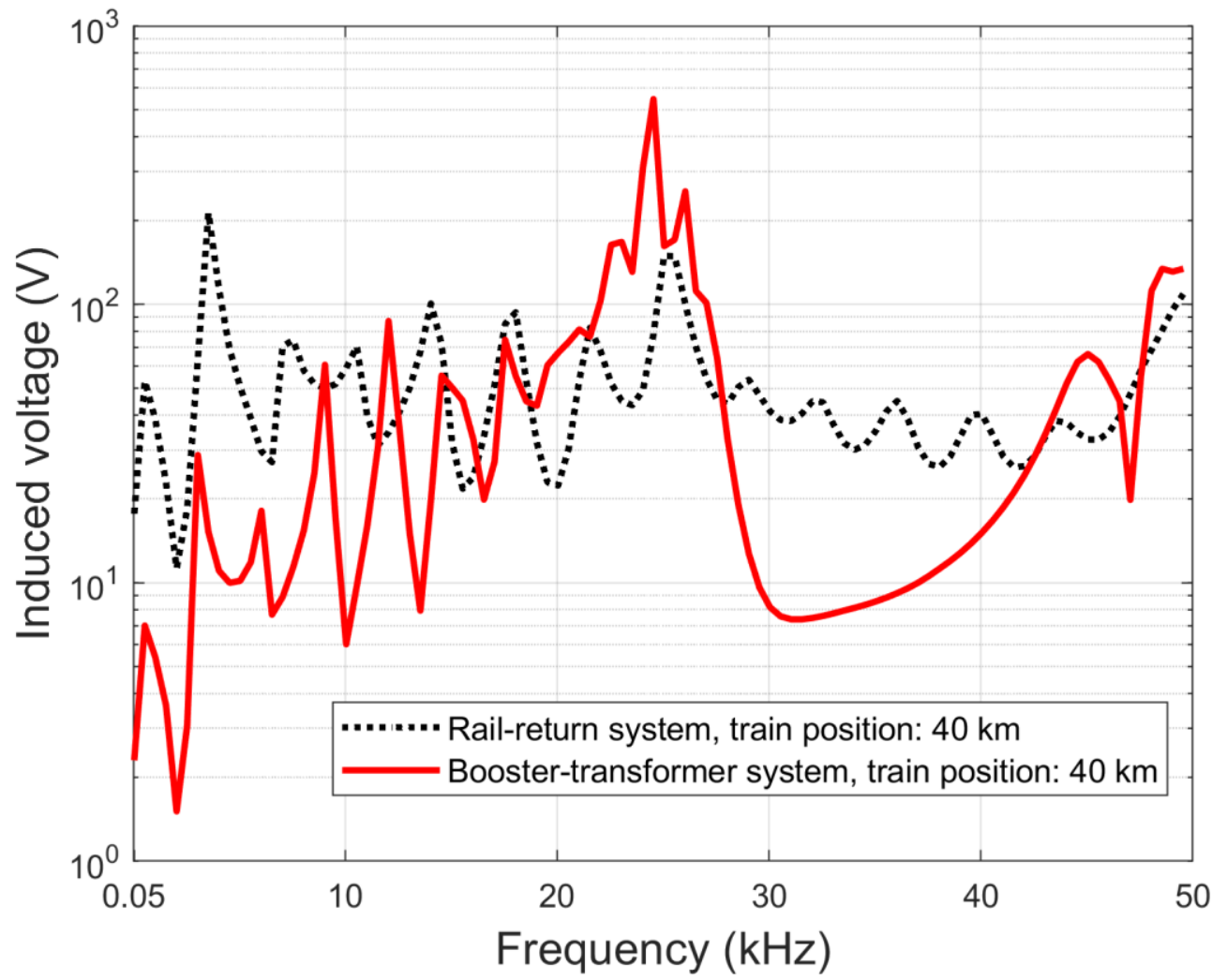

Figure 10. Induced voltage in the booster-transformer system, compared to the rail-return system.

\subsection{Simulation of the Auto-Transformer Electrification System}

The EMC performance of the AT electrification system is simulated and discussed in this section. The simulated AT system model is shown in Figure 11. As can be seen, auto-transformers are placed at $10 \mathrm{~km}, 20 \mathrm{~km}, 30 \mathrm{~km}$ and $40 \mathrm{~km}$ away from the substation. The inductance of the autotransformer is assumed to be $3 \mathrm{H}$. The train is located at $40 \mathrm{~km}$ away from the substation.

Comparing Figure 11 to Figure 9, there are two major differences between the simulated AT and BT systems: (1) there is no transformer placed in series with the OHL in the AT system; and (2) the autofeeder line (i.e., the overhead return conductor) of the AT system is connected to the negative voltage supply of $-25 \mathrm{kV}$ from the substation. 


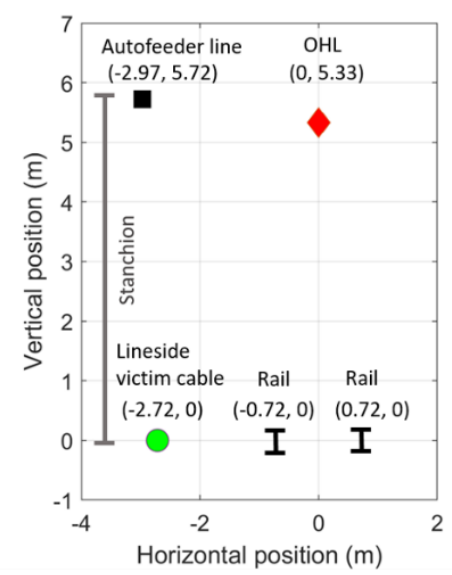

(a)

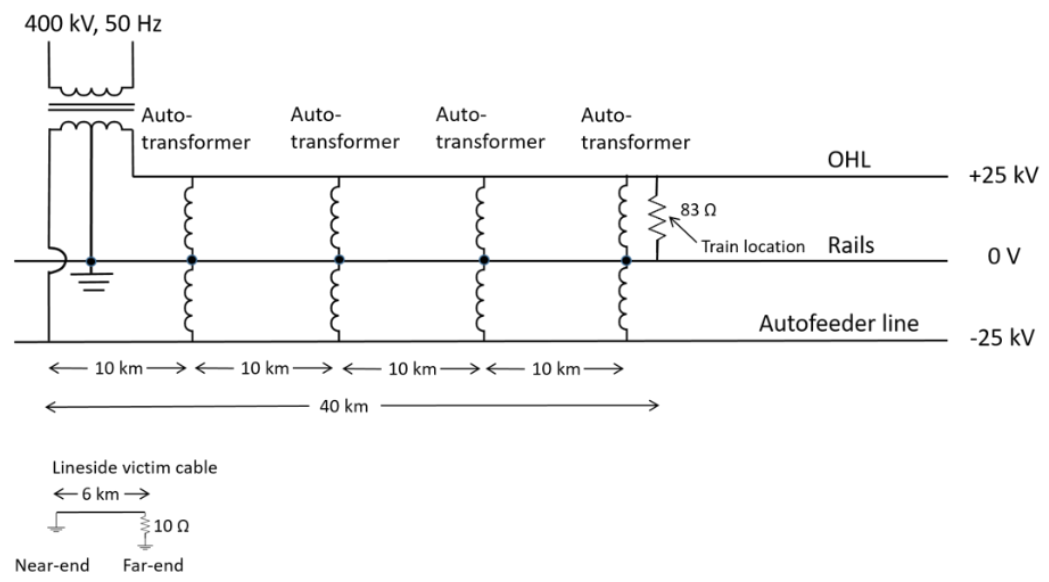

(b)

Figure 11. (a) Transverse view and (b) longitudinal view of the simulated auto-transformer electrification system.

Now let us focus on the EMC performance of the simulated AT electrification system. In Figure 12 , the induced voltage at the far-end of the lineside cable in the AT system is compared to that of the rail-return electrification system (with the train placed $40 \mathrm{~km}$ away from the substation). As can be seen, the AT system is able to significantly reduce interference to the lineside victim cable. Therefore, the lineside signalling failure risk can be effectively reduced by replacing the rail-return system with the AT system. Please note that there is no intention of comparing the EMC performances of the AT and BT systems. This is because the EMC performance of the BT or AT systems is largely dependent on the choice of the simulated configuration. Therefore, any claimed advantage of the AT system over the BT system or vice versa could be biased. 


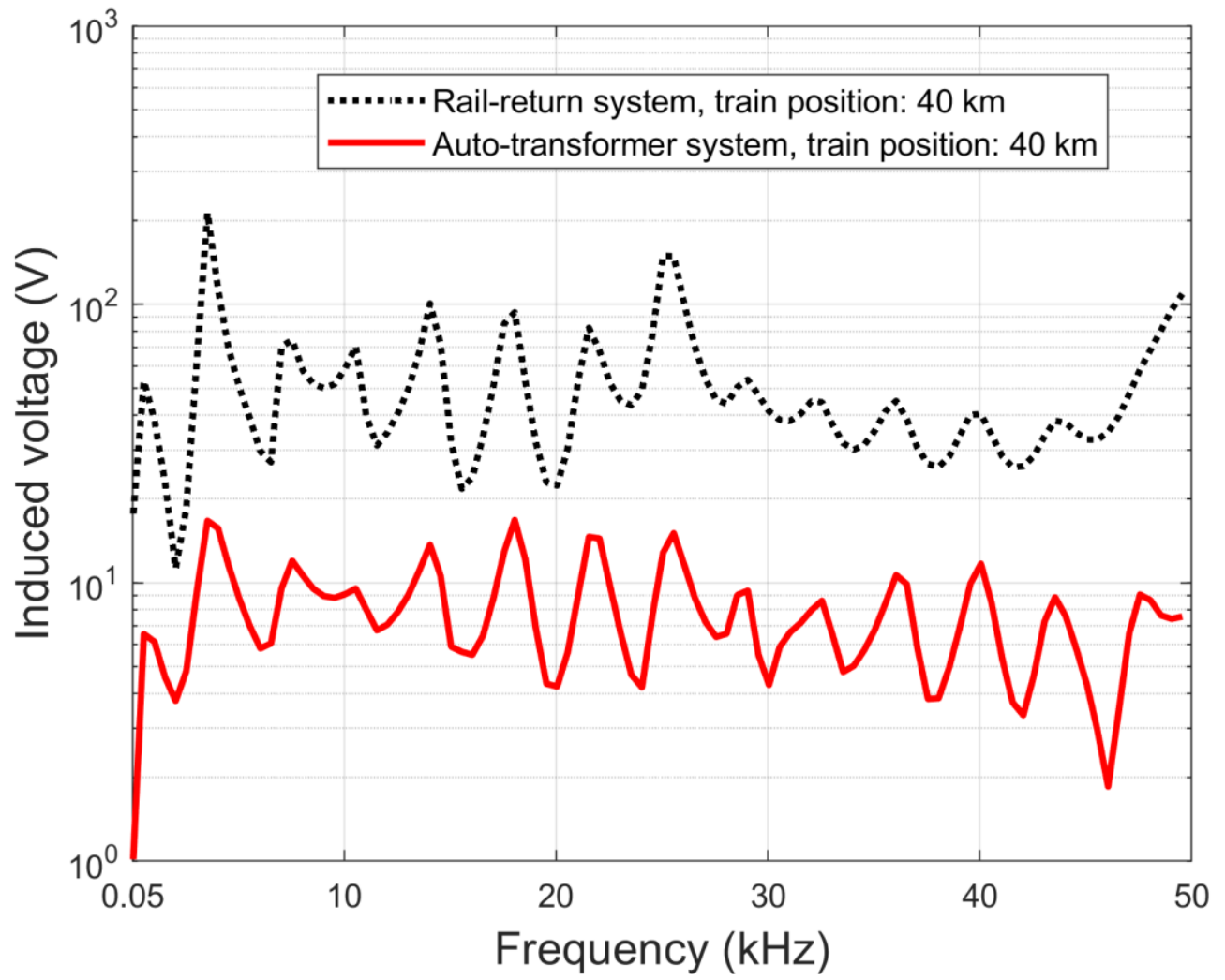

Figure 12. Induced voltage in the auto-transformer system, compared to the rail-return system.

As addressed in Section 2.2, the inductive impedance of the booster transformer can cause a voltage drop along the $\mathrm{OHL}$, resulting in a considerable voltage drop along the $\mathrm{OHL}$. This feature is verified in Figure 13 by comparing the voltage variation along the $\mathrm{OHL}$ in the $\mathrm{BT}$ (with a typical booster transformer inductance value of $100 \mathrm{mH}$ ) and AT systems. As can be seen in Figure 13, the voltage at each position along the $\mathrm{OHL}$ in the AT system is higher compared to that of the BT system. This is because the AT system is not subject to the relatively large voltage drops due to the inductance of the booster transformer. Moreover, it is interesting to notice in Figure 13 that the voltage along the $\mathrm{OHL}$ of the BT system experiences a stepped reduction at each booster transformer location. This behaviour is in line with the voltage-drop mechanism in BT systems (see Section 2.2). Clearly, the AT electrification system is shown to be able to maintain the high electric power required by the train. 


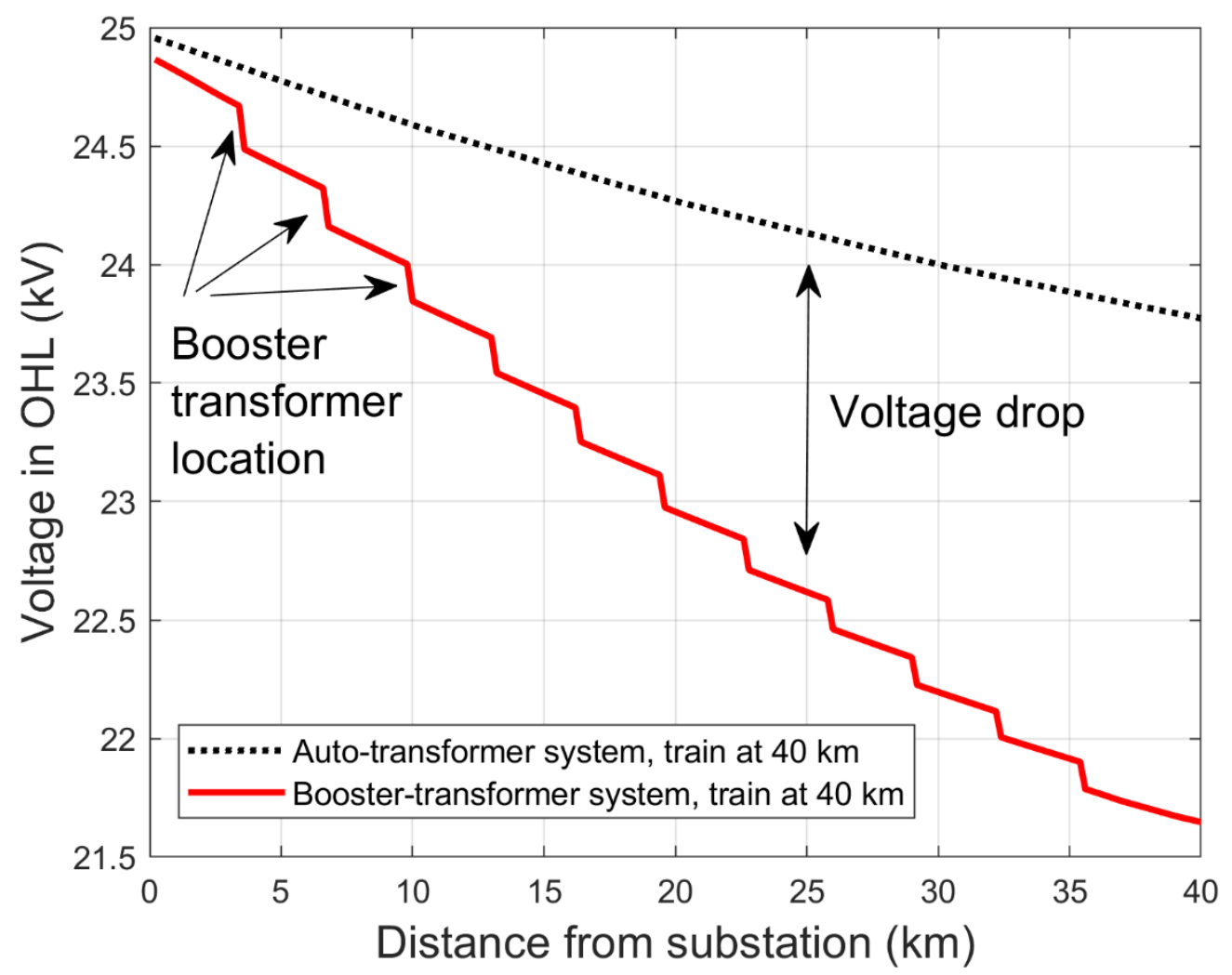

Figure 13. Voltage at different positions along the $\mathrm{OHL}$ in the auto-transformer and boostertransformer systems.

\section{Conclusions}

This article has raised the significance of EMC in modern railway electrification systems. The principles of the main railway electrification systems (i.e., the rail-return, booster-transformer, and auto-transformer systems) have been introduced, with a particular emphasis on the EMC perspective. The relative benefits and drawbacks of each electrification system have been discussed on a theoretical basis.

The theoretical discussion has been verified using the simulation of different railway electrification schemes. The result has shown that both the auto-transformer and boostertransformer systems can reduce the interference in the lineside signalling cable, compared to the rail-return system. The drawback of the booster-transformer system has been shown to be the significant voltage drop along the overhead power line. The voltage-drop issue can be improved using the auto-transformer system which is able to maintain high voltage during transmission. From this perspective, the auto-transformer system can be seen as a suitable option for heavyduty transportation, with a small electromagnetic disturbance to the lineside cabling system. 


\section{Acknowledgment}

The authors would like to thank colleagues of Expert Services Department of Eurofins York Ltd for their valuable discussion.

\section{References}

[1] F. Holmstrom, D. Turner, and E. Fernald, "Rail transit EMI-EMC," IEEE Electromagnetic Compatibility Magazine, vol. 1, no. 1, pp. 79-82, Jul. 2012.

[2] C. Christopoulos, Principles and Techniques of Electromagnetic Compatibility, 2nd ed. Boca Raton, F.L., USA: CRC Press, 2005.

[3] A. Ogunsola and A. Mariscotti, Electromagnetic Compatibility in Railways, 1st ed. New York, USA: Springer, 2013.

[4] E. Karadimou and R. Armstrong, "Test of rolling stock electromagnetic compatibility for cross-domain interoperability," IET Intelligent Transport Systems, vol. 10, no. 1, pp. 10-16, Jan. 2016.

[5] Y. Chen, R. White, T. Fella, S. Hillmansen, and P. Weston, "Multi-conductor model for AC railway train simulation," IET Electrical Systems in Transportation, vol. 6, no. 2, pp. 67-75, May 2016.

[6] T. Kneschke, "Simple method for determination of substation spacing for AC and DC electrification systems," IEEE Transactions on Industry Applications, vol. IA-22, no. 4, pp. 763-780, Jul. 1986.

[7] Railway electrification in Great Britain. Available: https://en.wikipedia.org/wiki/Railway_electrification_in_Great_Britain. [Accessed: 6-Oct2018].

[8] Railway technology. Available: https://www.railwaytechnology.com/contractors/electrification/selco-rt/attachment/selco-rt2/. [Accessed: 7Oct-2018].

[9] NR/GN/TEL/31106, Overview of electromagnetic coupling between traction systems and telecommunications cables, Issue 1, Jun. 2012. 
[10] C. R. Paul, Introduction to Electromagnetic Compatibility, 2nd ed. Hoboken, N.J., USA: John Wiley \& Sons, 2005.

[11] Y. Mochinaga, Y. Akatsuka, K. Arai, and M. Ono, "Development of three-winding transformer for shinkansen auto-transformer feeding system receiving extra-high voltage," IEEJ Transactions on Industry Applications, vol. 111, no. 3, pp. 237-244, Jan. 1991.

[12] Eurofins York Ltd (York EMC Services). Available: https://www.yorkemc.com. [Accessed: 27-Feb-2019].

[13] NR/SP/SIG/50003, Methodology for the demonstration of compliance with double rail reed track circuits on the DC railway, Issue 2, Feb. 2007.

\section{Author Biography:}

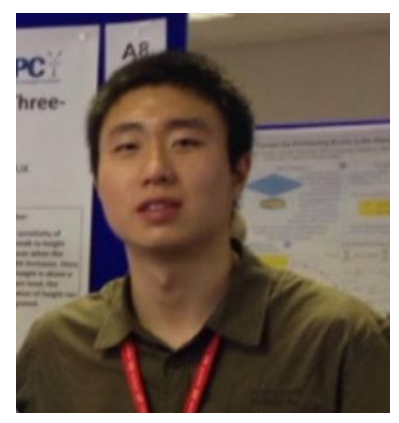

Zhouxiang Fei was born in Xi'an, China, in 1990. He received the B.Eng. degree in Electronics and Information Engineering from Northwestern Polytechnical University, Xi'an, China, in 2012, an M.Sc. degree (Distinction) in Wireless Communications from the University of Southampton, Southampton, U.K., in 2013, and a Ph.D. degree from High-Frequency Engineering Research Group at the University of Liverpool, Liverpool, U.K., in 2018. His doctoral research concerned numerical and experimental studies of crosstalk in complex cable bundles, with a particular emphasis on considering parameter variability using efficient statistical approaches.

From 2018, Dr. Fei is a senior EMC Consultant Engineer with a specialism in Rail EMC at Eurofins York Ltd, York, U.K., responsible for delivering consultancy solutions to the rail industry.

Dr. Fei is the recipient of the Best Paper Award at the International Conference on Computational Electromagnetics 2019 and the Best Student Paper Award at the 2017 IEEE Electrical Design of 
Advanced Packaging and Systems Symposium. He is the recipient of the student scholarship from the IEEE EMC Society. He was also selected as the Best EMC Paper Finalist for the 2016 IEEE International Symposium on EMC.

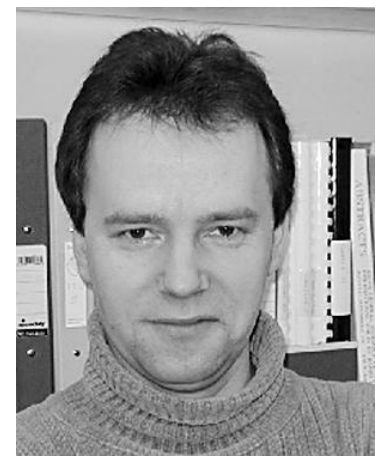

Tadeusz Konefal was born in Nottingham, U.K., in 1962. He received the B.Sc. degree in physics from the University of Sheffield, Sheffield, U.K., in 1987, and the D.Phil. degree in nondestructive testing from Cranfield Institute of Technology, Cranfield, U.K., in 1993.

From 1991 to 2006, he was a Research Assistant/Research Fellow in the Electronics Department, University of York, York, U.K., working on numerous projects in both Applied Electromagnetics and Communications groups. Since 2006, he has been working as a Senior EMC Engineer for York EMC Services, York. His current research interests include intermediate-level modeling design tools for EMC.

Dr. Konefal was awarded the Best Oral Paper Prize at the 4th European Symposium on EMC, Brugge, Belgium, in September 2000.

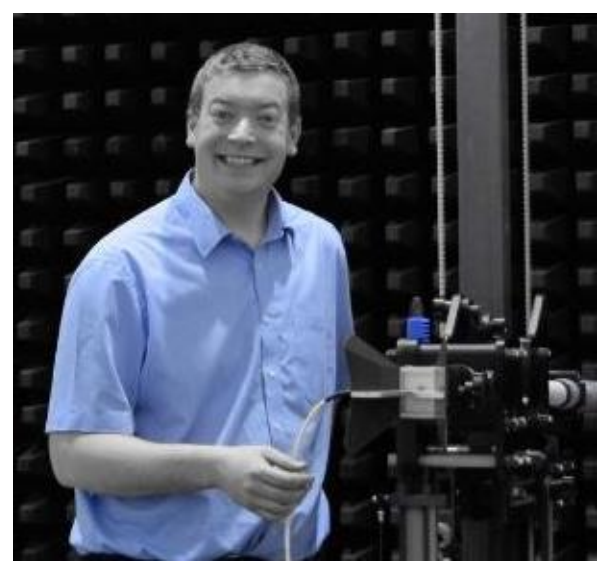

Rob has a PhD in Electronics from the University of York which he gained in 2013. Rob also holds a Master's degree and a Bachelor's degree in Physics. 
On completing his PhD in 2013, Rob joined the Expert Services department at York EMC Services (now Eurofins York) full time as an EMC Engineer, having worked part time on European funded projects while writing up his PhD.

Rob has worked on projects for customers in rail, automotive and industrial sectors. He has experience of bespoke and novel measurement systems, rail and automotive regulations and standards, EMC management and reverberation chambers including a specialisation in shielding effectiveness techniques.

Eurofins York's Expert Services activities are mainly in the Rail Environment but also encompasses Nuclear, Industrial, Defence, Automotive, and Research and Development sectors.

Rob is also responsible for our Training business unit and is Course Leader for a number of our courses including our Flagship 5-day "Fundamentals of EMC" and our bespoke rail course "Essentials of Railway EMC". 